\title{
Letters
}

\section{Active-Forced-Commutated Bridge Using Hybrid Devices for High Efficiency Voltage Source Converters}

\author{
Peng Li, Member, IEEE, Stephen J. Finney, and Derrick Holliday
}

\begin{abstract}
In high-power converters, the on-state characteristics of semiconductor devices dictate its efficiency performance even if the optimized topologies are adopted. This letter proposes an active-forced-commutated (AFC) bridge that employs the hybrid power devices of thyristor and insulated-gate bipolar transistor (IGBT) to operate as a voltage source converter or the building blocks of complex multistage high-voltage high-power converters. In this scheme, the thyristors are placed in the main power path that conducts for most of the fundamental period to lower the on-state losses; while the IGBT-based full-bridge (FB) chain-link is used for controlled (soft) transition and forced commutation of the main thyristor bridge, operating in short period. This stepped transition voltage also leads to minimized $d v / d t$ exerted on the interfacing transformer. To coordinate the operation of these two parts, the FB stack is designed to operate in a concave polygon stepped transition mode for the ordered turn-on and turn-off of thyristors according to different categories of commutation events. Detailed commutation analysis for the AFC-bridge is provided in this letter; also, high-level discussions and simulation results are presented to demonstrate its potential technical merits.
\end{abstract}

Index Terms-Active forced commutation (AFC), controlled transition, high efficiency, hybrid device, insulated-gate bipolar transistor (IGBT), thyristor, voltage source converter (VSC).

\section{INTRODUCTION}

$\mathbf{H}$ IGH-CAPACITY high-efficiency voltage source converters (VSCs) are the enabling technology for driving the realization of generic multiterminal high voltage direct current $(\mathrm{HVdc})$ transmission networks. VSC-based HVdc can address the weaknesses of using the conventional line commutated converter (LCC), namely, the commutation failure under weak ac networks, high reactive power consumption, and limited control flexibility. Thus, VSC has extended the role of HVdc into applications requiring flexible terminal voltage control, weak ac grid compatibility, rapid power flow reversal (without reversing the dc-link voltage polarity as in LCC), and multiterminal configuration [1], [2].

Manuscript received June 24, 2016; revised September 7, 2016 and October 4, 2016; accepted October 22, 2016. Date of publication November 14, 2016; date of current version January 20,2017. This work was supported by the Engineering and Physical Sciences Research Council under Grant EP/K035096/1.

The authors are with the Department of Electronics and Electrical Engineering, University of Strathclyde, Glasgow G1 1XW, U.K (e-mail: peng.li@ strath.ac.uk; stephen.finney@strath.ac.uk; derrick.holliday@strath.ac.uk).

Color versions of one or more of the figures in this letter are available online at http://ieeexplore.ieee.org.

Digital Object Identifier 10.1109/TPEL.2016.2622298
VSC topologies for HVdc applications have evolved from the two-level and monolithic multilevel converters to the modular multilevel converter (MMC) and its variants. Current MMC topologies are able to achieve true voltage scalability, system redundancy, and internal fault management. Also, the use of multilevel modulation leads to reduced switching losses and $d v / d t$ exerted on the transformers [3], [4].

Despite the stated benefits of VSC-HVdc, thyristor-based LCC-HVdc has maintained advantages in terms of capacity and efficiency; thus, it remains dominant in the large power evacuation through ultra-HVdc (UHVdc) links. These advantages result from the use of high capacity thyristors with extremely low on-state losses. For example, the $4.5 \mathrm{kV} / 1.8 \mathrm{kA}$ insulated-gate bipolar transistor (IGBT) module T1800GB45A has a typical forward voltage of $3.7 \mathrm{~V}$, whereas the on-state voltage of $4.8 \mathrm{kV} / 1.77 \mathrm{kA}$ thyristor T1551N48TOH is $1.57 \sim 1.7 \mathrm{~V}$. Several hybrid configurations of LCC and MMC have been put forward in attempt to achieve a tradeoff between efficiency and operational flexibility [5]-[7]. However, the current source nature of LCC in above solutions requires dc-link voltage reversal to change the power flow direction, reducing the compatibility with other VSC terminals in multiterminal $\mathrm{HVdc}$ networks.

This letter proposes the active-forced-commutated (AFC) bridge using hybrid switching devices (thyristor and IGBT) to operate as a VSC or basic building block of a complex UHVdc power converters. It employs thyristors to transfer the main power efficiently, whereas an IGBT-based full-bridge chain-link (FB-CL) is used to actively control the turn-on and turn-off of the main thyristor bridge by applying a stepped transition voltage with appropriate magnitude and polarity, which offers soft switching and forced commutation to the thyristors. In this manner, the VSC nature is established for the AFC-bridge; thus, the active and reactive power control can be decoupled. Compared to LCC, this solution enables the thyristor operation free of ac grid strength. Moreover, it offers dc-fault blocking capability and power flow reversal either with or without changing the dc-link voltage polarity, which is similar as the FB cell MMC in terms of functionality but at much lower losses. The AFC-bridge is expect to unlock the possibility of using VSC in UHVdc link ( $\pm 800 \mathrm{kV}$ or beyond) with similar efficiency of LCC. To ensure proper operation, the FB-CL of the proposed converter works in a concave polygon stepped transition (CPST) mode; also, it can act as the backup free-wheeling path during current sampling mismatch or when the load current level is below the thyristor latching current. Operation principle and modulation strategy of the AFC-bridge are provided in the letter. 


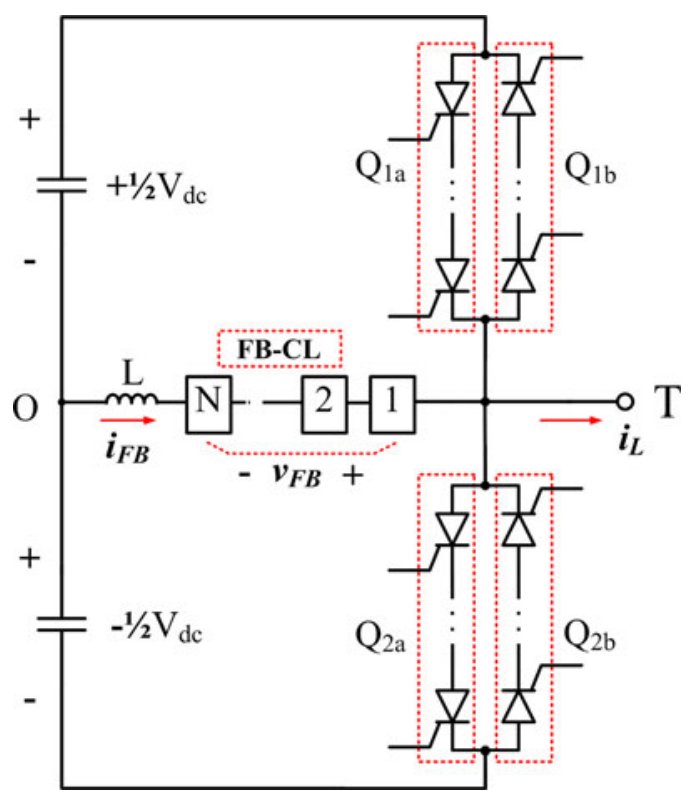

Fig. 1. Proposed AFC-bridge using hybrid power devices.

\section{PROPOSED AFC-BRIDGE}

\section{A. Operational Principle of the AFC-Bridge}

The configuration of the proposed AFC-bridge is depicted in Fig. 1, where series connected thyristors $Q_{1 \mathrm{a}}$ and $Q_{2 \mathrm{a}}$ are employed as the main power switches with antiparallel thyristor strings $Q_{1 \mathrm{~b}}$ and $Q_{2 \mathrm{~b}}$ as current free-wheeling paths for full power factor range. The commutation of thyristor bridge is guaranteed by the actively controlled FB-CL that provides reversible voltage to force the thyristors to turn off. This auxiliary FB-CL is a string of FB modules using the self-commutated IGBT, which is active only during thyristor commutation. Therefore, its average power dissipation is low and the associated cooling system is small, without significant impact on the overall efficiency and power density.

To ensure the ordered turn-on and turn-off of thyristors, one thyristor is fired at each instance based on the voltage-level command and current polarity, and the FB-CL acts as the freewheeling path when the load current is below the thyristor latching current or during any current sampling mismatch. In Fig. 1, if the AFC-bridge dc-link voltage is $V_{\mathrm{dc}}$ with neutral point $\mathrm{O}$, the FB-CL should be designed to have internal redundancy that allows the trajectory of its output voltage $v_{\mathrm{FB}}$ to go beyond the envelopes of $\pm 1 / 2 V_{\mathrm{dc}}$. When $v_{\mathrm{FB}}$ is higher (lower) than $+1 / 2 V_{\mathrm{dc}}\left(-1 / 2 V_{\mathrm{dc}}\right)$, the upper (lower) thyristor string $Q_{1 \mathrm{a}}\left(Q_{2 \mathrm{a}}\right)$ can be turned off provided its gate signal is removed. In another side, the turn-off of antiparallel devices $Q_{1 \mathrm{~b}}\left(Q_{2 \mathrm{~b}}\right)$ can be realized when $v_{\mathrm{FB}}$ is lower (higher) than $+1 / 2 V_{\mathrm{dc}}\left(-1 / 2 V_{\mathrm{dc}}\right)$. Also, the FB-CL offers stepped transition and zero voltage switching (ZVS) for the thyristor to be compatible with the critical $d v / d t$ and $d i / d t$ for device safe operation.

Over the majority of the operation period (thyristor conduction status), the FB-CL sustains a voltage of $\pm 1 / 2 V_{\mathrm{dc}}$. To block this voltage, if $V_{U}$ is the capacitor voltage on each FB unit, $N_{T}$ of them should be inserted into the FB-CL path; thus, (1) can be obtained. Also, a group of redundant FB modules are required in the FB-CL to supply a maximum output voltage larger than $1 / 2 V_{\mathrm{dc}}$ by $V_{\mathrm{C}}$. Suppose $N_{C}$ FB units are employed to generate this additional voltage $V_{\mathrm{C}}$ as in (2); therefore, the total number of FB units in the FB-CL $N$ is obtained by (3)

$$
\begin{aligned}
& N_{T} \cdot V_{\mathrm{U}}=1 / 2 V_{\mathrm{dc}} \\
& N_{C} \cdot V_{\mathrm{U}}=V_{\mathrm{C}} \\
& N=N_{T}+N_{C} .
\end{aligned}
$$

The AFC-bridge achieves dc-fault blocking capability by inhibiting the gate signals from both thyristors and IGBTs of the FB-CL. In this manner, the total FB-CL capacitor voltage can effectively decay the dc fault current.

\section{B. AFC-Bridge Commutation With FB-CL in CPST Mode}

As analyzed previously, when load current $i_{\mathrm{L}}$ is positive, commutation happens between the upper main thyristor $\left(Q_{1 \mathrm{a}}\right)$ and the lower antiparallel device $\left(Q_{2 \mathrm{~b}}\right)$ with other thyristors being turned off, whereas if $i_{L}$ is negative, $Q_{1 \mathrm{~b}}$ and $Q_{2 \mathrm{a}}$ will participate in the voltage-level transition. For symmetry, Fig. 2 interprets the commutation process of the AFC-bridge by assuming $i_{\mathrm{L}}$ in positive direction. As in Fig. 2, the FB-CL is modulated in a CPST mode with its voltage and current noted as $v_{\mathrm{FB}}$ and $i_{\mathrm{FB}}$, respectively, which is able to control the voltage and current waveforms of $Q_{1 \mathrm{a}}$ and $Q_{2 \mathrm{~b}}$. The full commutation process is shown in Fig. 2, where, for clear demonstration, the transition period is expanded relative to the conduction state. Detailed explanations for each stage of Fig. 2 are as follows.

1) $\left[t_{0}-t_{1}\right]$ : Initially, both $Q_{1 \mathrm{a}}$ and $Q_{2 \mathrm{~b}}$ are turned off while the FB-CL current $i_{\mathrm{FB}}$ supplies the load current; thus, with the current direction definition in Fig. 1, we have $i_{\mathrm{FB}}=i_{L}$ and $v_{\mathrm{TO}}=v_{\mathrm{FB}}$.

2) $\left[t_{1}-t_{2}\right]$ : With the increase of $v_{\mathrm{FB}}$ to $+1 / 2 V_{\mathrm{dc}}$, the voltage of $Q_{1 \text { a }}$ decreases to zero. Then, $Q_{1 \mathrm{a}}$ is triggered and $N_{C}$ units of the FB-CL are blocked (with blocking voltage $V_{C}$ ), making the output current commutate from the FBCL to $Q_{1 \mathrm{a}}$ under ZVS turn-on. In this period, the lower thyristors $Q_{2 \mathrm{a}}$ and $Q_{2 \mathrm{~b}}$ sustain the voltage of $+V_{\mathrm{dc}}$.

3) $\left[t_{2}-t_{3}\right]$ : The FB-CL current reduces to zero; and the full current flows through the thyristor $Q_{1 \mathrm{a}}$. This period is used for main power transfer and the AFC-bridge generates $+1 / 2 \mathrm{~V}_{\mathrm{dc}}$ on converter pole $\mathrm{T}$ relative to the dc neutral point $\mathrm{O}$.

4) $\left[t_{3}-t_{4}\right]$ : With the voltage-level transition command, the $Q_{1 \text { a }}$ gate signal is removed and the FB-CL voltage $v_{\mathrm{FB}}$ increases to $1 / 2 V_{\mathrm{dc}}+V_{C}$ by its redundant $\mathrm{FB}$ modules, facilitating a negative net voltage of $-V_{C}$ across the $Q_{1}$ a conduction loop (since $Q_{1 \mathrm{~b}}$ is not triggered), which forces the $Q_{1 \mathrm{a}}$ current to decrease. At the same time, $i_{\mathrm{FB}}$ rises in order to support the full load current.

5) $\left[t_{4}-t_{5}\right]:$ At $t_{4}$, the $Q_{1 \text { a }}$ current decreases to negative peak value, establishing the required reverse bias voltage. After its reverse recovery process, a voltage of $-V_{C}$ on $Q_{1 \mathrm{a}}$ and $Q_{1 \mathrm{~b}}$ lasts until $t_{5}$ with the load current fully transferred to the FB-CL. $Q_{2 \mathrm{a}}$ and $Q_{2 \mathrm{~b}}$ block the voltage of $V_{\mathrm{dc}}+V_{C}$.

6) $\left[t_{5}-t_{6}\right]$ : Since $Q_{1 \mathrm{a}}$ has been forced turned off, the FB-CL voltage $v_{\mathrm{FB}}$ starts to decrease from $1 / 2 V_{\mathrm{dc}}+$ $V_{C}$ to $-1 / 2 V_{\mathrm{dc}}$ in a stepped transition manner, which offers the soft transitions to the thyristors. 


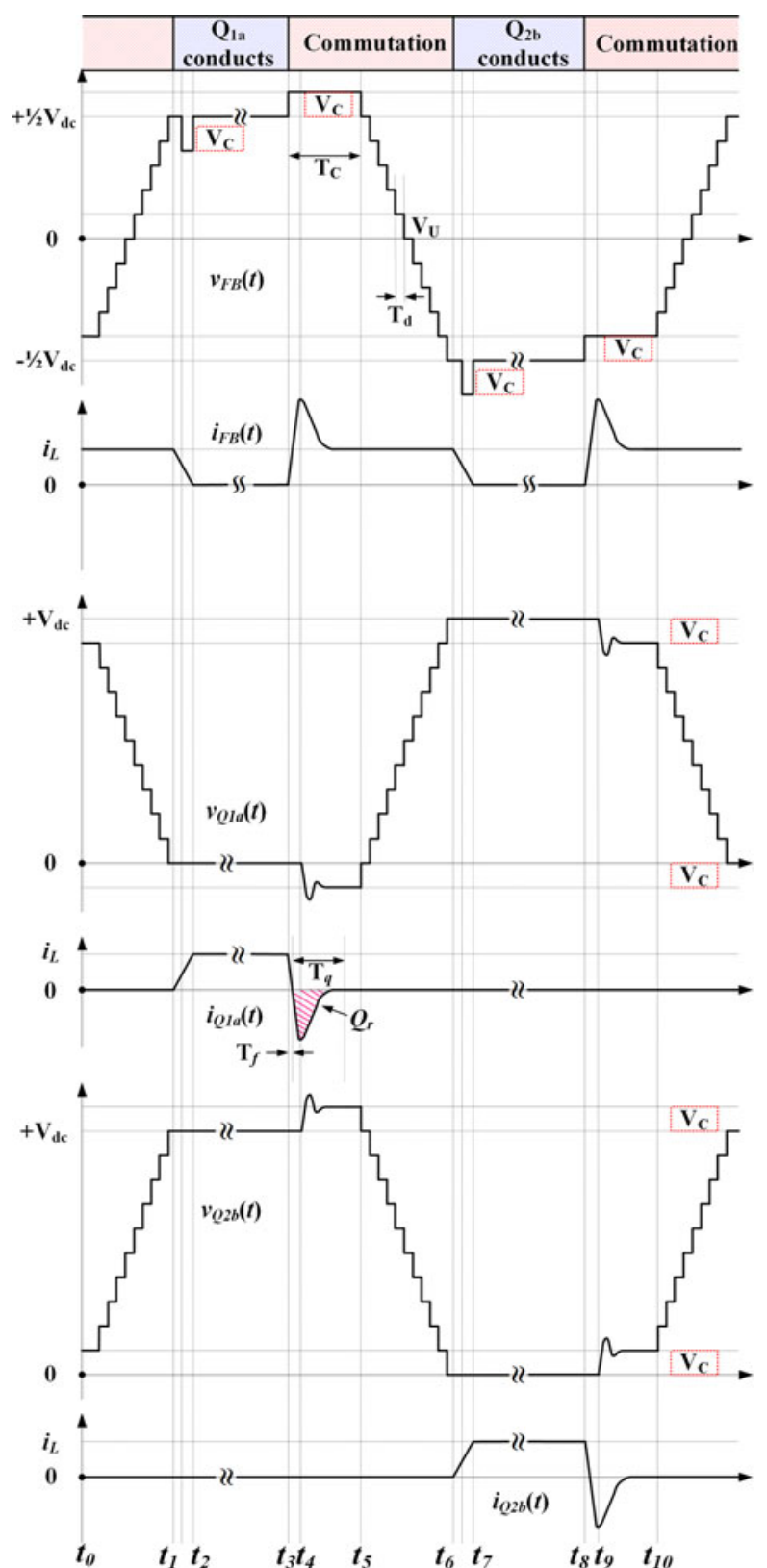

Fig. 2. Commutation of the AFC-bridge (when load current $i_{L}>0$ ) with FB-CL operating in CPST mode.

7) $\left[t_{6}-t_{7}\right]$ : At $t_{6}$, the blocking voltage of $V_{\mathrm{dc}}$ is established on $Q_{1 \mathrm{a}}$ and $Q_{1 \mathrm{~b}}$, whereas the voltage on $Q_{2 \mathrm{a}}$ and $Q_{2 \mathrm{~b}}$ becomes zero. With $Q_{2 \mathrm{~b}}$ being triggered and the $N_{C}$ FB modules being disabled, the output current transits from the FB-CL to $Q_{2 \mathrm{~b}}$ in ZVS turn-on manner.

Then, $Q_{2 \mathrm{~b}}$ carries the full load current during $t_{7}-t_{8}$ and the similar forced commutation and stepped transition processes are performed by the FB-CL to execute the voltage-level transition command. After $t_{10}$, the initial state in $t_{0}-t_{1}$ starts and the same processes are repeated for positive $i_{L}$.

It is noticed that the principle power is transferred through the low loss thyristors during intervals of $t_{2}-t_{3}$ and $t_{7}-t_{8}$ that form the majority of the operation period; also, the switching losses are minor due to the stepped transition of the FB-CL. When $i_{L}$ is in negative direction, the symmetrical process of

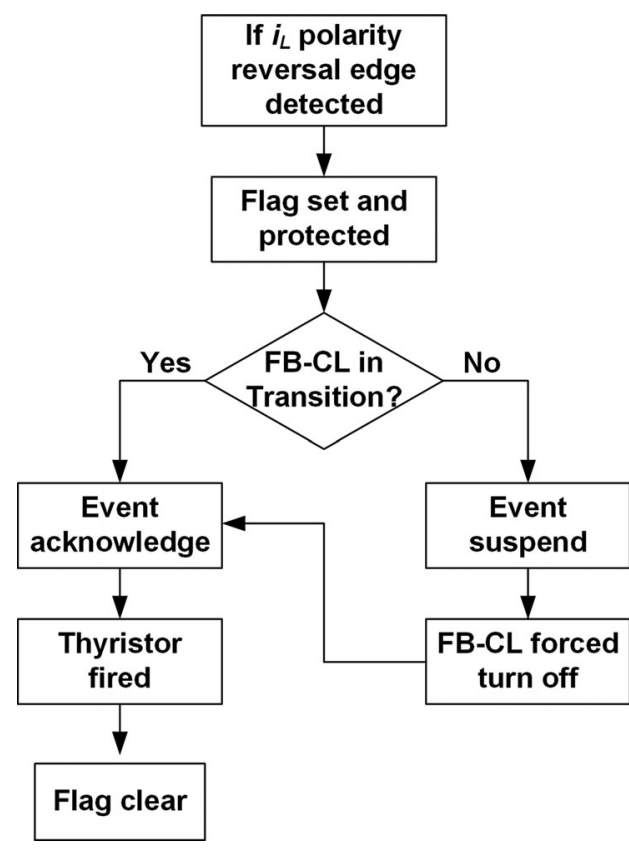

Fig. 3. Response to the current natural commutation event.

Fig. 2 will apply to the FB-CL $Q_{1 \mathrm{~b}}$ and $Q_{2 \mathrm{a}}$. The voltage balancing of FB-CL submodules can be realized using its redundant switching states to charge or discharge the selected capacitors based on the sorting results [8].

\section{Current Natural Commutation Event Management}

To guarantee the causal, ordered, and reliable operation of the AFC-bridge, only one thyristor is fired at each instance based on the voltage-level command and current polarity; and it must be forced turned off by the FB-CL before the gate signal moves to next device. During this period, the FB-CL is able to serve as the free-wheeling path for current sampling mismatch and zerocrossing current lower than the thyristor latching current. In order to minimize the free-wheeling time of FB-CL, the current natural commutation (zero crossing) events should be managed as in Fig. 3, where two categories of event triggers are responded by the AFC-bridge as follows.

If current zero crossing is detected during the voltage-level transitions, the event will be acknowledged directly; and after the FB-CL is disabled, the proper thyristor for conducting the reversed current flow will be fired, whereas if the current zero crossing happens out of the voltage-level transition periods, the FB-CL is utilized to force the previous thyristor to turn off, then its antiparallel device will be fired to carry the reversed current. This regime ensures any previously triggered thyristor must be turned off by the FB-CL before next thyristor is turned on and the FB-CL itself provides a free-wheeling path for seamless current operation. As a result, the ordered and causal commutation of the AFC-bridge can be facilitated.

\section{Converter Dimensioning Guidelines}

From Fig. 2, the total charge required for forced turn-off of the thyristor can be estimated by the integration of the output current $\left(i_{L}\right)$ over the thyristor negative voltage duration $T_{\mathrm{c}}$ plus the thyristor recovered charge $Q_{r}$, which is expressed by (4). 


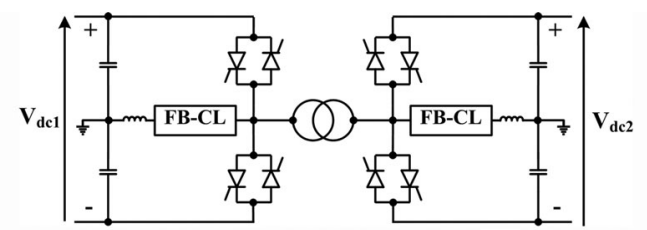

(a)

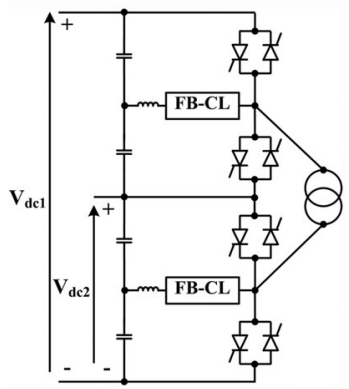

(b)

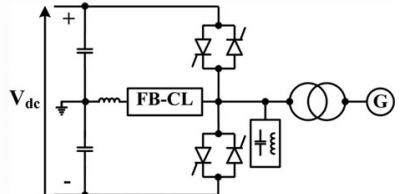

(c)

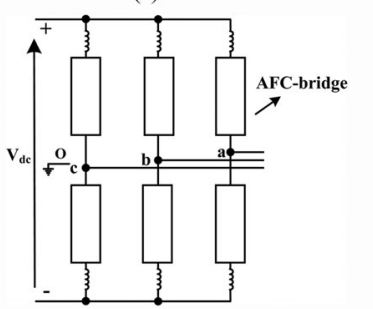

(d)

Fig. 4. AFC-bridge applied in HVdc transmission system: (a) F2F dc-dc converter; (b) dc-dc AT; (c) dc-ac converter; and (d) MMC arm.

For a given allowable voltage ripple percentage of $\kappa$ on the FB capacitors, the FB unit capacitance $C_{U}$ is determined by (5), where $\kappa$ should satisfy the inequality of (6) to ensure that the total capacitor voltage of the FB-CL remains greater than $1 / 2 V_{\mathrm{dc}}$. After the thyristor is turned off, the FB-CL conducts the load current $i_{L}$ and provides an orderly transition with short dwelling time $T_{d}\left(T_{d}<<T_{C}\right)$ at each voltage step. For a sinusoidal output current $i_{L}(t)=I_{a c} \cos (\omega t-\theta)$ and based on (4)-(5), the FB unit capacitance can be calculated by (7)

$$
\begin{aligned}
Q_{C}= & \int_{t_{i}}^{t_{i}+T_{C}} i_{L}(t) d t+Q_{r} \\
Q_{C}= & \kappa\left(1 / 2 V_{\mathrm{dc}}+V_{\mathrm{C}}\right) \cdot \frac{C_{U}}{N}=\kappa V_{\mathrm{U}} \cdot C_{U} \\
& \kappa<V_{c} /\left(1 / 2 V_{\mathrm{dc}}+V_{\mathrm{C}}\right) \\
C_{U}= & \frac{1}{\kappa V_{\mathrm{U}}}\left[\int_{\theta / \omega-1 / 2 T_{C}}^{\theta / \omega+1 / 2 T_{C}} I_{a c} \cos (\omega t-\theta) d t+Q_{r}\right] \\
= & \frac{I_{\mathrm{ac}} T_{C} \cdot \operatorname{sinc}\left(1 / 2 \omega T_{C}\right)+Q_{r}}{\kappa V_{\mathrm{U}}} .
\end{aligned}
$$

The FB-CL branch inductance $L$ determines the $d i_{\mathrm{FB}} / d t$ during the thyristors turn-on and turn-off. It must be sized such that the maximum permitted current ramp rate $\zeta$ of the adopted thyristors is not exceeded. Also, to ensure reliable turn-off of the thyristor, the reverse bias time $T_{C}$ should be larger than device turn-off time $T_{q}$; and the current falling time $T_{f}$ must be shorter than $T_{\mathrm{C}}-T_{q}$. Therefore, the constraints for calculating $L$ can be summarized as in (8)

$$
\frac{i_{L}}{T_{C}-T_{q}} \leq \frac{V_{C}}{L} \leq \zeta
$$

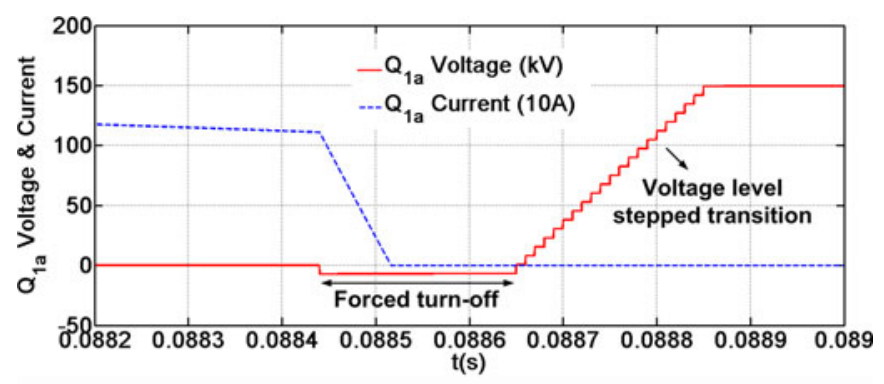

(a)

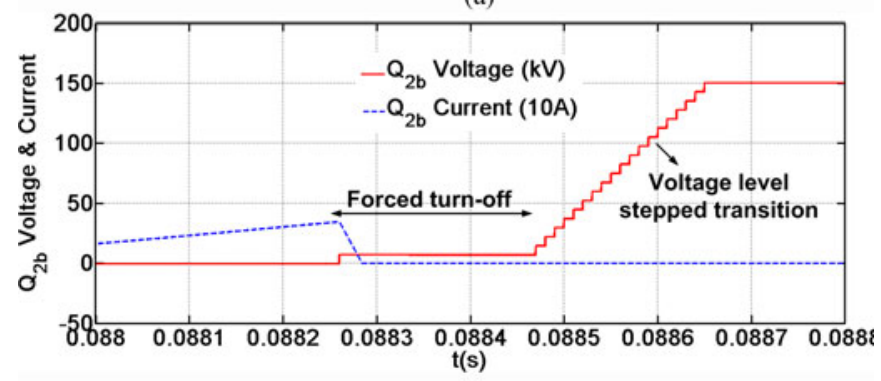

(b)

Fig. 5. Zoomed-in switching waveforms for thyristors in the AFC-bridge: (a) turn-off and stepped transition of $Q_{1 \mathrm{a}}$; and (b) turn-off and stepped transition of $Q_{2 \mathrm{~b}}$.

\section{Performance EVAluAtion AND Discussion}

The AFC-bridge is possible to operate as an independent VSC or the building blocks of many other converters such as the front-to-front $(\mathrm{F} 2 \mathrm{~F}) \mathrm{dc}-\mathrm{dc}$ converter, dc autotransformer (AT), and MMC (see Fig. 4 [9], [10]).

In dc-dc applications, the AFC-bridge could be operated with trapezoidal waveform. The FB-CL is used to generate the slope for soft transition of the main thyristor devices while the majority of the power is transferred through the thyristors. Due to the high operational power factors of the AFC-bridge in its dc transformer configuration, the antiparallel thyristors can be low current rated.

If the AFC-bridge operates as a dc-ac converter or needs to supply black-start capability in a dc transformer, the dc-rail clamping period, zero-voltage-level duration, and voltage-level transition slope of its ac voltage waveform can be manipulated to vary the modulation index in full range. In these cases, the FB-CL may operate longer period for better voltage wave quality but with limited sacrifice of converter efficiency. The triplen harmonic injection could be used to further extend the modulation range of the AFC converter [8], [11]. An alternative option is to use the selective harmonic elimination (SHE). However, the number of switching angles is limited by the thyristor commutation speed. The tuned filters are required to eliminate low order harmonics for ac grid connection.

For a generic verification of the AFC-bridge commutation, SHE with one switching angel per quarter cycle is employed for a simulation study. The specifications are as follows: dc-link voltage: $150 \mathrm{kV}$, FB cell capacitor: $5 \mathrm{mF}$, FB number: $N=11$, $N_{T}=10, N_{C}=1$, FB-CL inductance: $750 \mu \mathrm{H}$, three-phase power rating: $160 \mathrm{MVA}$, and ac side peak phase current: $1.5 \mathrm{kA}$.

The zoomed-in version of the thyristor forced turn-off in the AFC-bridge is shown in Fig. 5, where the upper main thyristor $Q_{1 \mathrm{a}}$ and lower antiparallel thyristor $\mathrm{Q}_{2 \mathrm{~b}}$ both have forced commutation and voltage-level stepped transition processes 


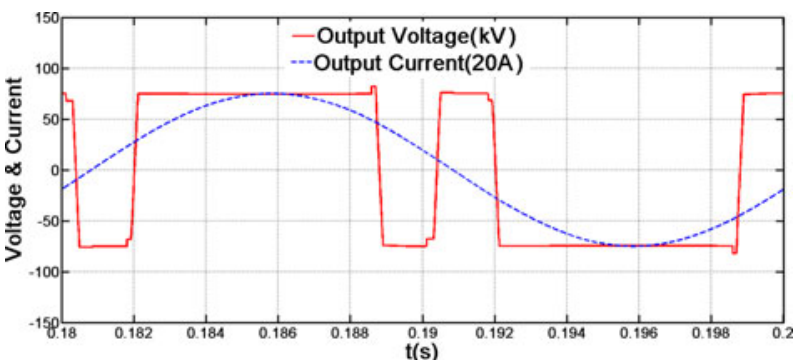

(a)

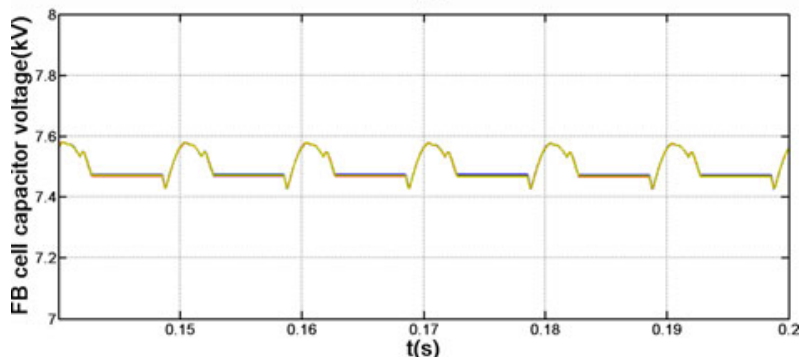

(b)

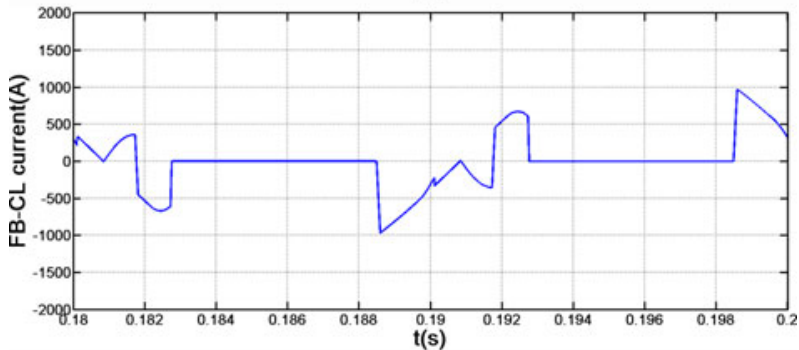

(c)

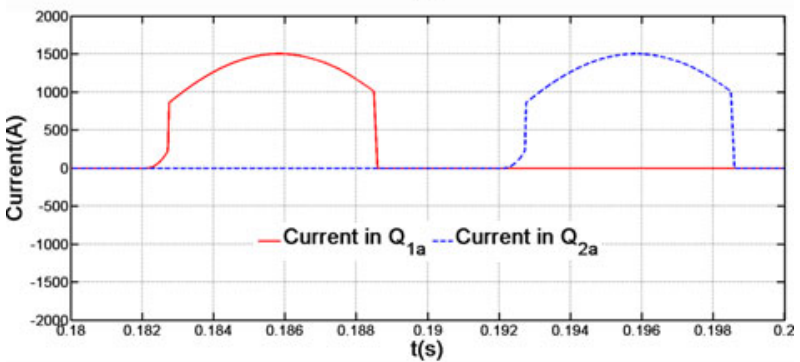

(d)

Fig. 6. Key waveforms of the AFC-bridge: (a) output voltage and current; (b) FB capacitor voltage balancing; (c) FB-CL current; and (d) current carried by thyristor $Q_{1 \text { a }}$ and $Q_{2 \mathrm{a}}$.

offered by the FB-CL as in Fig. 2. It is noticed that, to save simulation time, the reverse recovery of the thyristor is not modeled in this case study. Since this process finishes within the forced turn-off period, it will not influence the presented modulation scheme.

The key waveforms of the AFC-bridge in fundamental time scale are summarized in Fig. 6. The output voltage with one switching angle per quarter cycle and output current with $1.5 \mathrm{kA}$ peak value are shown by Fig. 6(a). Observe in Fig. 6(b), the FB module capacitor voltages can be kept balanced by the redundant switching states of the AFC-bridge. According to Fig. 6(c), the FB-CL only conducts during short periods of thyristor commutation and load current zero crossing; also, by utilizing the blocking states of the FB-CL, its current decays naturally and the load current can be smoothly routed into the thyristor.
In this way, the majority of the load current is carried by the main thyristors $Q_{1 \mathrm{a}}$ and $Q_{2 \mathrm{a}}$ alternatively in this high power factor case as in Fig. 6(d); and their antiparallel devices are exposed to low currents. When power factor decreases, the current distribution in antiparallel thyristors will increase.

\section{CONCLUSION}

This letter has proposed an AFC-bridge with hybrid devices of thyristors and IGBT for high efficiency HVdc converters. Instead of having live ac grid voltage as prerequisite for successful line commutation of the thyristors in LCC, the AFCbridge employs its FB-CL circuit to offer soft transition and forced commutation to the thyristors. In this manner, their fully controlled turn-on and turn-off are realized, which allows the AFC-bridge to operate the thyristors as a VSC with weak ac grid compatibility under full power factor range and black-start capability from a given dc-link voltage. Furthermore, by using the symmetrical thyristors as main power paths, the AFC-bridge has even lower semiconductor losses than the half-bridge MMC, but offers equivalent system functionalities as the FB cell MMC. These functions such as the dc fault blocking, continuous operation under reduced dc-link voltage as well as bipolar dc-link voltage, and bidirectional current capability ensure its coordination with both VSC and LCC terminals. The proposed AFC-bridge is highly applicable in HVdc systems such as F2F dc-dc converter and dc-dc AT; while in its dc-ac scenarios, a group of tuned filters are necessary to remove the dominant low order harmonics.

\section{REFERENCES}

[1] W. F. Long et al., "Application aspects of multiterminal DC power transmission," IEEE Trans. Power Del., vol. 5, no. 4, pp. 2084-2098, Oct. 1990.

[2] X. Wang and B. T. Ooi, "High voltage direct current transmission system based on voltage source converters," in Proc. 21st Annu. IEEE Power Electron. Spec. Conf. Rec., 1990, pp. 325-332.

[3] A. Nami, L. Jiaqi, F. Dijkhuizen, and G. D. Demetriades, "Modular multilevel converters for HVDC applications: Review on converter cells and functionalities," IEEE Trans. Power Electron., vol. 30, no. 1, pp. 18-36, Jan. 2015

[4] S. Debnath, Q. Jiangchao, B. Bahrani, M. Saeedifard, and P. Barbosa, "Operation, control, and applications of the modular multilevel Converter: A review," IEEE Trans. Power Electron., vol. 30, no. 1, pp. 37-53, Jan. 2015.

[5] M. A. Parker and S. J. Finney, "Design of a fault-tolerant tandem converter for a multi-MW superconducting offshore wind turbine generator," in Proc. 2015 IEEE Int. Conf. Ind. Technol., Seville, Spain, 2015, pp. 969-975.

[6] M. Jafar, M. Molinas, T. Isobe, and R. Shimada, "Transformer-less series reactive/harmonic compensation of line-commutated HVDC for offshore wind power integration," IEEE Trans. Power Del., vol. 29, no. 1, pp. 353-361, Feb. 2014.

[7] T. H. Nguyen, D. C. Lee, and C. K. Kim, "A series-connected topology of a diode rectifier and a voltage-source converter for an HVDC transmission system," IEEE Trans. Power Electron., vol. 29, no. 4, pp. 1579-1584, Apr. 2014.

[8] P. Li, G. P. Adam, D. Holliday, and B. Williams, "Controlled transition fullbridge hybrid multilevel converter with chain-links of full-bridge cells," IEEE Trans. Power Electron., vol. 32, no. 1, pp. 23-38, Jan. 2017.

[9] G. P. Adam, I. A. Gowaid, S. J. Finney, D. Holliday, and B. W. Williams, "Review of dc-dc converters for multi-terminal HVDC transmission networks," IET Power Electron., vol. 9, pp. 281-296, 2016.

[10] P. Li, S. J. Finney, and D. Holliday, "Thyristor based modular multilevel converter with active full-bridge chain-link for forced commutation," in Proc. 2016 IEEE 17th Workshop Control Model. Power Electron., 2016, pp. $1-6$.

[11] C. Oates, K. Dyke, and D. Trainer, "The use of trapezoid waveforms within converters for HVDC," in Proc. 2014 16th Eur. Conf. Power Electron. Appl., 2014, pp. 1-10. 